\title{
Patients with Complex Chronic Diseases: Perspectives on Supporting Self-Management
}

\author{
Mary Ann Sevick, ScD, RN ${ }^{1,2,3,4}$, Jeanette M. Trauth, $P h D^{1,4}$, Bruce S. Ling, MD, MPH', \\ Roger T. Anderson, $P h D^{5}$, Gretchen A. Piatt, $P h D^{6}$, Amy M. Kilbourne, $P h D, M P H^{7,8}$, \\ and Robert M. Goodman, PhD'
}

\begin{abstract}
${ }^{1}$ Center for Health Equity Research and Promotion, VA Pittsburgh Healthcare System (151-C), Pittsburgh, Pennsylvania, USA; ${ }^{2}$ Geriatric Research Education and Clinical Center, VA Pittsburgh Healthcare System, Pittsburgh, Pennsylvania, USA; ${ }^{3}$ School of Medicine, University of Pittsburgh, Pittsburgh, Pennsylvania, USA; ${ }^{4}$ Graduate School of Public Health, University of Pittsburgh, Pittsburgh, Pennsylvania, USA; ${ }^{5}$ Department of Public Health Sciences, Penn State College of Medicine, Hershey, Pennsylvania, USA; ${ }^{6}$ Diabetes Institute, University of Pittsburgh Medical Center, Pittsburgh, Pennsylvania, USA; ${ }^{7}$, Ann Arbor National Serious Mental Illness Treatment Research and Evaluation Center, Ann Arbor, Michigan, USA; ${ }^{8}$ Department of Psychiatry, University of Michigan, Ann Arbor, Michigan, USA; 9 School of Health, Physical Education, and Recreation, Indiana University, Bloomington, Indiana, USA.
\end{abstract}

A Complex Chronic Disease (CCD) is a condition involving multiple morbidities that requires the attention of multiple health care providers or facilities and possibly community (home)-based care. A patient with CCD presents to the health care system with unique needs, disabilities, or functional limitations. The literature on how to best support self-management efforts in those with CCD is lacking. With this paper, the authors present the case of an individual with diabetes and end-stage renal disease who is having difficulty with self-management. The case is discussed in terms of intervention effectiveness in the areas of prevention, addiction, and self-management of single diseases. Implications for research are discussed.

KEY WORDS: comorbidity; chronic disease; self care; health behavior; patient compliance.

J Gen Intern Med 22(Suppl 3):438-44

DOI: $10.1007 / \mathrm{s} 11606-007-0316-\mathrm{Z}$

(c) Society of General Internal Medicine 2007

\section{INTRODUCTION}

A Complex Chronic Disease (CCD) is a condition involving multiple morbidities, that requires the attention of multiple health care providers or facilities and possibly community (home)-based care. A patient with CCD presents to the health care system with unique needs, disabilities, or functional limitations. ${ }^{1}$ A CCD typically involves multiple self-management requirements or complex social support needs, or both. Consider the following case as an example.

Mr. $\mathrm{S}$ is a 65-year-old male diagnosed with type 2 diabetes 15 years ago. About 2 years ago Mr. S developed kidney failure secondary to his diabetes, and began a thrice-weekly regimen of hemodialysis. Mr. S remained stable, regularly attending dialysis treatments until 6 months ago, when his wife died unexpectedly. Since then he began missing treatments. His glycemic control worsened and his interdialytic weight gains increased significantly. He was diagnosed with and began treatment for depression, but, Mr. S admitted that with his wife gone, he doesn't see the point of taking care of himself anymore. He no longer performs glucose checks, and frequently misses the numerous medications that he is prescribed. $\mathrm{He}$ finds his dietary regimen to be confusing and because he is not accustomed to cooking for himself, Mr. S finds it more convenient to eat at fast food restaurants. Mr. S sees his nephrologist (Dr. D) every month. Dr. D feels frustrated because he encourages Mr. S to comply with his recommendations without success. Likewise, $\mathrm{Mr}$. S is frustrated because he feels Dr. D lectures him at every visit and doesn't allow time for him to discuss matters of most concern to him-the loss of his wife and other difficulties that have interfered with his ability to manage his care.

This scenario is not unusual. According to data from the 1998 U.S. National Medical Expenditure Panel Survey, the number of people with chronic illness is growing and projected to reach 171 million by the year 2030. Almost $1 / 2$ of those with a chronic disease have multiple chronic conditions. ${ }^{2,3}$ Medicare data show that $65 \%$ of beneficiaries have multiple chronic conditions. ${ }^{4}$ The growing prevalence of multimorbidity has been confirmed in a number of studies. ${ }^{5-12}$

Nevertheless, the literature lacks detail regarding how health care professionals can best support the self-management efforts of those with more than 1 chronic disease. The literature on self-management has been derived mainly from theoretical and empirical work in the areas of prevention, addiction, and adherence to medical regimens for single-disease states. This paper discusses that body of work, with an eye toward identifying potentially useful approaches for supporting CCD self-management. The discussion is arranged according to general subject headings suggested by our case scenario, including: negotiation of the goals of care, communicating with patients, engaging patients in behavior change, reducing information processing burden, and minimizing the negative impact on health-related quality of life. The article concludes with an agenda for future research.

\section{Negotiation of the Goals of Care}

According to Thorne, the goals of chronically ill patients often diverge from those of their health care providers. Patients are 
trapped between their effort to obtain appropriate medical care and a desire to live a normal life. ${ }^{13}$ This description is likely to be particularly applicable to those trying to manage multiple diseases and is consistent with our example. Dr. D is frustrated by his patient's lack of compliance to the medical regimen, whereas $\mathrm{Mr}$. S struggles to manage his life and conditions in the face of having lost his wife. When faced with an apparent lack of agreement regarding the nature of the problem, how can providers elicit in patients like Mr. S a desire to engage in good self-management?

Efforts to increase patient participation in care through collaborative goal-setting and planning of treatment have been suggested by Wagner et al., ${ }^{14}$ to be an essential component of chronic disease management. Collaborative goal-setting has been found to be effective in interventions to enhance diabetes self-management, ${ }^{15}$ and reduce health risks. ${ }^{16,17}$ Motivational interviewing (MI) is a theory-based counseling approach that has been shown in the health promotion and substance abuse literature to be effective in engaging patients and providers in mutual goal-setting around self-management. ${ }^{18}$ With MI, the counselor helps clients verbally express their own reasons for and against behavior change, how current health behavior may conflict with their health goals, and how their current behavior or health status affects their ability to achieve their life goals. MI requires a nonjudgmental, empathetic, and encouraging communication style. ${ }^{19}$ Whereas MI techniques have not been widely applied to CCDs, such approaches may be particularly helpful for engaging patients such as Mr. S. in contemplating what he thinks is possible regarding his selfcare requirements. If effective in $\mathrm{CCD}$, MI may result in activated patients and plans of care that are patient-centered.

\section{Communicating with Patients}

Patient-provider communication is not only important for engaging patients in self-care, it continues to be important as patients become informed participants in their care. ${ }^{20-22}$ In studies of patient-physician communication, patients report that communication skills are 1 of the top 3 competencies that a physician should possess, ranking it higher than other attributes such as promotion of preventive care, consideration of costs to the patient, correct use of technology, and cooperation with other health care professionals. ${ }^{23}$ Table 1 summarizes the findings of a systematic review of the literature on the association of communication characteristics and patient outcomes. ${ }^{24}$ Quality communication has been shown to be directly associated with optimal self-care, ${ }^{25}$ to result in better continuity of care, and to increase provision of preventive services. ${ }^{26}$

Although they have not been evaluated in the CCD population, a number of interventions have been tested to improve the process of patient-provider communication. Patient-targeted approaches have been shown to improve health outcomes and include techniques such as patient activation through skills training (e.g., coaching patients to take a more active role in the clinic visit) and use of previsit questionnaires to identify pertinent patient concerns. ${ }^{21,22,27,28}$ These approaches may be particularly useful for CCD patients such as Mr. S, who are likely to have complicated educational and other needs that would otherwise go unnoticed in health care encounters that are driven solely by the provider.

Provider-based approaches such as communication skills training, discussion of behavior change, and interventions to
Table 1. Association of Provider Behavior and Patient Outcomes

\begin{tabular}{|c|c|}
\hline $\begin{array}{l}\text { Verbal behaviors associated } \\
\text { with positive patient outcomes }\end{array}$ & $\begin{array}{l}\text { Verbal behaviors associated } \\
\text { with negative patient outcomes }\end{array}$ \\
\hline \multicolumn{2}{|l|}{ Interaction style: } \\
\hline Empathy & Passive acceptance \\
\hline Passive physician behavior & $\begin{array}{l}\text { Negative social-emotional } \\
\text { interactions }\end{array}$ \\
\hline Dominant physician behavior & Formal behavior \\
\hline Tension release & Antagonism \\
\hline Friendliness & Interruptions \\
\hline Courtesy & One-way information flow \\
\hline Listening & Directiveness \\
\hline \multirow[t]{4}{*}{ Talking at the patient's level } & Dominance \\
\hline & Attentiveness \\
\hline & Irritation \\
\hline & Nervousness, anxiety or tension \\
\hline \multicolumn{2}{|l|}{ Interaction content: } \\
\hline $\begin{array}{l}\text { Statements of reassurance, } \\
\text { support, }\end{array}$ & $\begin{array}{l}\text { High rates of biomedical } \\
\text { questioning }\end{array}$ \\
\hline Encourages patient questions & $\begin{array}{l}\text { Extensive feedback during the } \\
\text { concluding part of the visit }\end{array}$ \\
\hline Provides explanations & $\begin{array}{l}\text { Expresses opinions during } \\
\text { physical exam }\end{array}$ \\
\hline \multicolumn{2}{|l|}{$\begin{array}{l}\text { Allows patient's point of view to } \\
\text { guide the conversation at the } \\
\text { conclusion of the visit }\end{array}$} \\
\hline \multicolumn{2}{|l|}{ Positive reinforcement } \\
\hline \multicolumn{2}{|l|}{ Addresses problems of daily living } \\
\hline \multicolumn{2}{|l|}{ Asks questions of the patient } \\
\hline \multicolumn{2}{|l|}{ Addresses psychosocial issues } \\
\hline \multicolumn{2}{|l|}{ Shares medical data } \\
\hline \multicolumn{2}{|l|}{ Discusses treatment effects } \\
\hline \multicolumn{2}{|l|}{$\begin{array}{l}\text { Summarizations and clarifying } \\
\text { statements }\end{array}$} \\
\hline \multicolumn{2}{|l|}{$\begin{array}{l}\text { Orienting the patient during the } \\
\text { physical exam }\end{array}$} \\
\hline \multicolumn{2}{|l|}{ Interaction time devoted to: } \\
\hline \multicolumn{2}{|l|}{ Education } \\
\hline \multicolumn{2}{|l|}{ The encounter } \\
\hline The history & \\
\hline
\end{tabular}

Beck RS, et al., 2003. ${ }^{24}$ Systematic review of studies $(n=14)$ employing audiotapes, videotapes, or neutral observers

improve patient-centeredness have shown variable results with regards to their effects on patent satisfaction and health outcomes. ${ }^{29-31}$ Multilevel interventions targeting both the patient and provider have also been developed with 1 study reporting a decrease in mortality among a geriatric population and improvement in functional status in which provider education and patient activation techniques were employed. ${ }^{32}$

\section{Engaging Patients in Behavior Change}

In addition to good communication, those caring for patients with CCD must be skilled in fostering behavior change. To understand the deterioration in Mr. S's current self-management behavior and the leverage points for possible intervention, we must first consider how individuals, in general, change their health behaviors.

Figure 1 is a representation of the common determinants of behavior change. ${ }^{33}$ The concepts and variables listed in Figure 1 are derived mainly from 3 well-known theories/ models: The Health Belief Model, Social Cognitive Theory, and the Theory of Reasoned Action. ${ }^{33}$ Three critical determinants of a person's intentions or behaviors can be found in these theories and include ..."1) the person's attitude toward per- 
Background influences

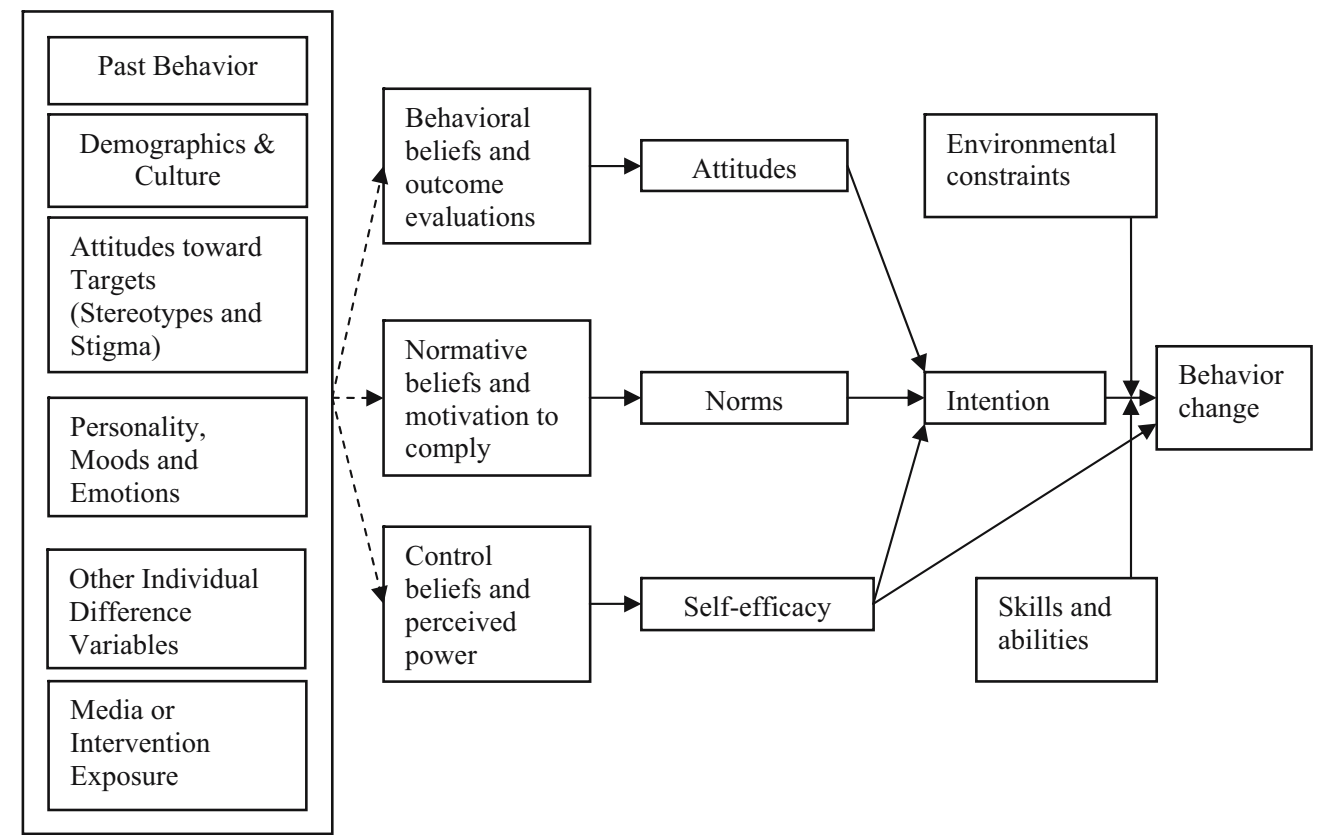

Figure 1. A general model of the determinants of behavior change. Taken from Committee on Communication for Behavior Change in the 21 st Century: Improving the Health of Diverse Populations, Board on Neuroscience and Behavioral Health, Institute of Medicine of the National Academies. Chapter 2: Theory in, Speaking of Health: Assessing Health Communication Strategies for Diverse Populations. The National Academies Press, Washington, D.C. 2002. page 42.

forming the behavior, which is based on one's beliefs about the positive and negative consequences (i.e., costs and benefits) of performing [the] behavior; 2) perceived norms, which include the perception that those with whom the individual interacts most closely support the person's adoption of the behavior and that others in the community are performing the behavior; and, 3) self-efficacy, which involves the person's confidence that he or she can perform the behavior under a variety of challenging circumstances." 34

With regard to our case, it is not clear to what extent Mr. S. understands the serious nature of his diseases or the consequences of nonadherence. He does not seem to have concluded that the benefits of self-management are worth the costs. In addition, Mr. S. has lost his wife, an important source of support for self-management of his diabetes and end-stage renal disease. It is not clear if there are others in his social network who can support him in his efforts to adhere to his regimen. Finally, Mr. S. has likely been told that his glycemic control has worsened and that he is consuming too much sodium and, as our case states, he feels as though he is being lectured by his physician. Such encounters with health care professionals are not likely to inspire Mr. S's self-confidence in his ability to manage his condition.

Very little behavior change research has been conducted in CCD patient populations. A number of meta-analyses of studies in patients with diabetes, a single (but arguably complicated) disease, have shown that traditional approaches to patient education may not be sufficient for helping patients with self-management. Ellis et al. ${ }^{35}$ demonstrated that diabetes self-management intervention approaches employing behavioral methods (e.g., goal setting, problem solving, cognitive reframing) are more effective than traditional didactic education in producing and maintaining behavior changes. Norris showed that the degree of glycemic control is directly related to the frequency of contact and that intervention effects attenuate within 2-3 months of the intervention, suggesting that continued contact may be required to sustain effects. ${ }^{36}$ A recent metaanalysis of 6 randomized trials in diabetes tentatively concluded that social support interventions affect patient self-care and outcomes. ${ }^{37}$ In their synthesis of the literature, Marks et al. ${ }^{38}$ show that interventions to enhance self-efficacy (e.g., incremental goal setting, self-monitoring and self-appraisal, problem solving, modeling, etc.) to be effective in improving behavioral and clinical outcomes in a variety of patient populations.

Multiple diseases are likely to require the introduction of multifactorial self-management regimens. Although they do not include CCD patient populations, multifactorial behavioral interventions do appear in the literature (e.g., the Diabetes Prevention Program, ${ }^{39}$ the Multiple Risk Factor Intervention Trial, ${ }^{40}$ and Look Ahead ${ }^{41}$ ). The goal of these studies is to examine risk factor reductions that can occur through behavior change, rather than to test the effectiveness of alternative self-management strategies. For example, Look Ahead is an ongoing clinical trial to determine whether weight loss among obese people with diabetes results in a reduction in cardiovascular events. To accomplish weight loss, Look Ahead involves a 5 -year intervention that includes an intensive behavioral weight loss intervention (i.e., weekly meetings for 6 months, biweekly meetings for the rest of the first year, with the frequency and mode of meetings decreasing in intensity over the subsequent 4 years). Whereas some important insights into the impact of weight loss on cardiovascular risk in obese people with diabetes will be gained from Look Ahead, the goal is not to determine the best approach for engaging patients in better self-management. Furthermore, such an intensive intervention is not likely to be feasible within a health service 
delivery system. Such studies provide health care professionals with limited information on best approaches for engaging patients in good self-care.

The results of studies comparing single versus multifactorial behavioral interventions in patients with single diseases (diabetes, hypertension) or unhealthy lifestyle behaviors (smoking, sun exposure, and high fat diet) have varied. ${ }^{42,43,44}$ Consequently, in helping CCD patients with self-management, the literature is not clear if self-care regimens requiring multiple behavior changes should be introduced simultaneously or sequentially.

Lorig et al. have developed a Chronic Disease Self-Management Program that includes generic content on exercise, symptom management, managing negative emotions, physician-patient communication, nutrition, fatigue management, and other topics that would be applicable to patients with any condition including those with multimorbidity. Whereas the program has been found to be effective in improving a variety of participant outcomes, it is not clear to what extent it is equally effective for those with CCD versus uncomplicated disease states. ${ }^{45-47}$

\section{Reducing Information Processing Burden}

Even the best informed, motivated, self-confident patients with CCD may fail in their efforts at self-management because of the complexity of information that must be manipulated for making good self-management decisions. Because problemsolving occurs within a person's short-term memory, ${ }^{48,49}$ when memory capacity is exceeded, patients will resort to heuristics or "rules of thumb" that result in less than optimal decisionmaking. ${ }^{50}$ Even if health care professionals succeed in helping patients solve problems and make the initial behavioral changes, research has shown that new behaviors are often not maintained. ${ }^{34,51}$ The reason for this is perhaps because of the fact that information vigilance (i.e., maintaining information needed for good decision-making in short-term memory) is burdensome. Consequently, as new behaviors become routine (e.g., taking a daily pill with breakfast) patients begin to pay less attention to what they are doing and relapse to former behavior patterns. ${ }^{52,53}$

Two meta-analyses do suggest that information burden may play a role in self-management. In a systematic review of adherence to diabetes medications, Cramer $^{54}$ showed adherence to be inversely related to the number of doses prescribed per day. In a meta-analysis of regimen adherence in several patient populations, DiMatteo, showed that patients are more adherent to circumscribed regimens (e.g., medication taking) than regimens requiring pervasive behavior change that impose greater information processing demands on the patient (e.g., diet). ${ }^{55}$

In our case, consider the information that Mr. S should consider in deciding what to eat for lunch. As a person with diabetes, he should know the carbohydrate content of the meal he plans to eat. As a person on dialysis he should limit his dietary potassium, phosphorus, and sodium. If Mr. S has experienced protein energy malnutrition (common in dialysis patients), his dietitian may have urged him to eat more calories and high-quality protein. Complicating this picture is the fact that single foods have multiple nutritional components, with differing health consequences depending on the condition of the patient. For example, increasing one's intake of fresh vegetables and legumes (a common recommendation for those with diabetes), may result in consumption of additional potassium and phosphorus (which should be limited in the dialysis diet).

The literature on information processing/vigilance with regard to self-management in $\mathrm{CCD}$ is lacking. However, information management in patient decision-making is likely to be a significant problem in CCD not only because of the complexity of regimens, but because many chronic diseases are also associated with deficits in cognitive function. ${ }^{56-64}$ Those with CCD are often older and, thus, normal age-related declines in cognitive function ${ }^{65}$ may also interfere with $\mathrm{CCD}$ self-management. ${ }^{66}$

One approach to minimizing information processing burden are Interactive Health Communication Applications (IHCAs), which are computer-based information packages that combine health information with social support, decision support, or behavior change support. IHCAs that have been evaluated in the literature include self-management educational programs for children with asthma; online discussion groups for those living with breast cancer or family caregivers of those with dementia; and dietary management programs. In a recent meta-analysis of 24 RCTs involving 3,739 participants who had a single chronic disease, Murray et al. ${ }^{67}$ found IHCAs appear to have largely positive effects on users in that users tend to become more knowledgeable, feel better socially supported, and have improved behavioral and clinical outcomes compared to nonusers.

\section{Minimizing Negative Impact on Health-Related Quality of Life (HRQL)}

HRQL, a standard outcome in medical care and research ${ }^{68-70}$ is defined as, "those attributes valued by patients, including: their resultant comfort or sense of well-being; the extent to which they [are] able to maintain reasonable physical, emotional, and intellectual function; and the degree to which they retain their ability to participate in valued activities within the family, in the work place, and in the community". There are 3 main processes linking self-management of CCD to HRQL: 1) direct effects inherent to the disease(s); compounded by: 2) effects from the prescribed treatment, including adverse and beneficial effects; and, 3) psychosocial strain or distress from coping with disease or treatment.

Regarding our scenario, the direct effect of disease on Mr. S's HRQL include physical symptoms, functional disability, psychosocial and role limitations, and loss of vitality owing to diabetes complicated by end-stage kidney disease. The impact of the treatment regimen on HRQL includes the need for Mr. S to adhere to his diabetes medication and dietary regimen, and to monitor his glycemic control. As a patient on hemodialysis, Mr. S must devote 3 days each week to his dialysis treatments, adhere to a renal diet, and take additional medications. Given his high interdialytic weight gains, $\mathrm{Mr}$. S is likely to experience cramping and hypotension during dialysis and to feel "washedout" afterward. Mr. S may also experience improved wellbeing from clearance of renal solutes and hemodynamic stability. ${ }^{71-73} \mathrm{Mr}$. S is likely to have undergone a long period of adaptation and adjustment to living with diabetes and kidney failure. Like Mr. S, people with $\mathrm{CCD}$ are likely to be older and, because of the loss of friends and family to death, may have a reduced social network. In our case, Mr. S has lost his wife, which simultaneously adds to his stress and reduces 
his ability to adapt. As noted previously, patients who experience net negative effects of CCD treatments may decide that the cost, in terms of HRQL, may outweigh the benefits of treatment and, like Mr. S., may choose not to adhere to the regimen. Such choices may result in tension between the patient who wants to normalize his life and the clinician whose goal is to optimize clinical outcomes.

Interventions to improve or maximize HRQL would be expected to have positive benefits for self-management. For example, controlling symptoms associated chronic disease and its treatment would be expected to improve capacity and willingness to perform self-management tasks. ${ }^{74,75}$ Health care delivery system interventions to enhance care coordination and continuity may improve HRQL and, in turn, reduce barriers to self-management. A key area where patient HRQL gains have been demonstrated is in interventions to improve the transition from institutional (e.g., hospital) to home setting, ${ }^{76-79}$ although improvements are not consistently shown. ${ }^{80}$ Combining patient education with postdischarge management has also been shown to be effective in improving HRQL in patients with respiratory disease. ${ }^{81}$

\section{IMPLICATIONS FOR RESEARCH}

It is important to reiterate that research pertaining to the patient experience with CCD is very limited. Because of the difficulties inherent in examining associations or causal relationships in very heterogeneous samples, research pertaining to self-management has focused on patients with uncomplicated disease states or very circumscribed management regimens, or both. Consequently, caution must be used in drawing conclusions about the best approaches for enhancing self-management in those with CCD. Additional research is needed to examine best methods for engaging and activating self-care activities, creating and sustaining behavior change, and enhancing quality of life in those who must self-manage multiple diseases.

Much of the empirical work related to behavior change is based upon theories and frameworks developed for the purpose of disease prevention and health promotion. It is important to recognize that, owing to the unique needs of patients with CCDs, theories related to behavior change and self-management developed in less complicated patient populations may not be generalizable to CCD. Qualitative research may play a key role in gaining a better understanding of the experience of self-management of patients with CCD, for the purpose of developing interventions that will address their unique needs and preferences.

MI and other techniques for negotiating patient-centered treatment goals may be useful for engaging CCD patients in self-care. Research is needed on acceptability and effectiveness of various communications approaches for helping patients anticipate their preferences for future health states. Research is needed on the effectiveness of patient-centered care models and techniques in terms of regimen adherence, patient satisfaction, health outcomes, and costs.

Research is needed on the extent to which behavioral techniques shown to be effective in health promotion, disease prevention, and management of single disease states are effective in supporting self-management in those with CCD. In particular, given that $\mathrm{CCD}$ is likely to require multifactorial behavior change, research is needed on the most effective approach for introducing multiple self-management requirements (i.e., prioritizing and sequencing self-management requirements versus simultaneous introduction). Patients with CCD are perhaps more likely than those with single diseases to experience fluctuations in their health status. Research would be helpful on best methods for supporting self-management in the face of changing circumstances. Given the fluctuating health status of patients with CCD and the fact that other researchers have shown behavioral effects to diminish after interventions are withdrawn, research is needed to determine the frequency of continued contacts needed to sustain longterm effects.

Given the complexity of self-management tasks required of CCD patients, research is needed on intervention approaches to minimize information processing burden. Computer-based programs may be useful in this regard, but such programs have been developed for and tested in patients experiencing single chronic diseases. Human Computer Interaction research is needed to design hardware and software applications that represent the cognitive tasks associated with managing a CCD. Research is needed to evaluate the extent to which such applications reduce the burden of self-management, aid in optimal self-management decisions, and improve patient outcomes.

\section{CONCLUSIONS}

In this paper, we have identified a number of potentially useful approaches for supporting self-management in CCD. Additional research to develop and evaluate intervention approaches is needed to improve the care of this growing population of patients with more than 1 chronic disease.

Acknowledgments: The work of this paper was supported by the Center for Health Equity Research and Promotion, VA Pittsburgh and VA Philadelphia Health Care Systems (Grant HFP01063).

Corresponding Author: Mary Ann Sevick, ScD, RN; Center for Health Equity Research and Promotion and the Geriatric Research Education and Clinical Center, VA Pittsburgh Healthcare System (151-C), Pittsburgh, Pennsylvania 15240, USA (e-mail: sevick@pitt. edu).

\section{REFERENCES}

1. Managing Complexity in Chronic Care. Arlington, VA: Department of Veterans Affairs, Office of Research and Development; 2006.

2. Partnership for Solutions. Chronic Conditions: Making the Case for Ongoing Care. Baltimore: Johns Hopkins University Press; 2004.

3. Anderson G, Horvath J. The growing burden of chronic disease in America. Public Health Reports. 2004;119:263-70.

4. Wolff JL, Starfield B, Anderson G. Prevalence, expenditures, and complications of multiple chronic conditions in elderly. Arch Intern Med. 2002;162:2269-76.

5. van den Akker M, Buntinx F, Metsemakers JF, Roos S, Knottnerus JA. Multimorbidity in general practice: prevalence, incidence, and determinants of co-occurring chronic and recurrent diseases. J Clin Epidemiol. 1998;51:367-75.

6. Schellevis FG, van der Velden J, van der Lisdonk E, van Eijk JTM, van Weel C. Comorbidity of chronic diseases in general practice. J Clin Epidemiol. 1993;46:469-73.

7. van Weel C. Chronic diseases in general practice: the longitudinal dimension. Eur J Gen Pract. 1996;2:17-21. 
8. Boyd CM, Darer J, Boult C, Fried LP, Boult L, Wu AW. Clinical Practice guidelines and quality of care for older patients with multiple comorbid diseases. JAMA. 2005;294:716-24.

9. Fortin M, Bravo G, Hudon C, Vanasse A, Lapointe L. Prevalence of multimorbidity among adults seen in family practice. Ann Fam Med. 2005;3:223-8.

10. Menotti A, Mulder I, Nissinen A, Giampaoli S, Feskens EJ, Kromhout D. Prevalence of morbidity and multimorbidity in elderly male populations and their impact on 10-year all-cause mortality: The FINE study. J Clin Epidemiol. 2001;54:680-6.

11. Zambrana Garcia JL, Velasco Malagon MJ, Diez Garcia F, Cruz Caparros G, Martin Escalante MD, Adarraga Cansino MD. Characteristics of patients with multiple disease hospitalized in Internal Medicine services. Rev Clin Esp. 2005;205:413-7.

12. Knottnerus JA, Metsemakers JFM, Höppener O, Limonard CBG. Chronic illness in the community and the concept of "social prevalence". Fam Pract. 1992;9:15-21.

13. Thorne S. Patient-provider communication in chronic illness: a health promotion window of opportunity. Fam Community Health. 2006;29:4S$11 \mathrm{~S}, \mathrm{p} .5 \mathrm{~S}$

14. Wagner EH, Bennett SM, Austin BT, Greene SM, Schaefer JK, Vonkorff M. Finding common ground: patient-centeredness and evidence-based chronic illness care. J Altern Complement Med 2005;11 Suppl 1:S7-15.

15. Fisher EB, Brownson CA, O'Toole ML, Shetty G, Anwuri VV, Glasgow RE. Ecological approaches to self-management: the case of diabetes. Am J Public Health. 2005;95:1523-35.

16. Alexy B. Goal setting and health risk reduction. Nurs Res. 1985;34:283-8.

17. Puczynski S, Phelps K, Wilke A, et al. Collaborative goal setting to improve lifestyle behaviors: lessons learned from NOPCRN. Ann Fam Med. 2005;2:S60-62.

18. Resnicow K, Dilorio C, Soet JE, Ernst D, Borrelli B, Hecht J. Motivational interviewing in health promotion: it sounds like something is changing. Health Psychol 2002;21:444-51.

19. Rollnick S, Butler CC, Stott N. Helping smokers make decisions: the enhancement of brief intervention for general medical practice. Patient Educ Couns. 1997;31:191-203.

20. Wagner EH, Austin BT, Davis C, Hindmarsh M, Schaeffer J, Bonom A. Improving chronic illness care: translating evidence into action. Health Aff (Millwood). 2001;20:64-78.

21. Greenfield S, Kaplan S, Ware JE. Expanding patient involvement in care- effect on patient outcomes. Ann Intern Med. 1985;102:520-8.

22. Kaplan SH, Greenfield S, Ware JE. Assessing the effects of physicianpatient interactions on the outcomes of chronic disease. Med Care. 1989;27:S110-S127.

23. McBride CA, Shugars DA, DiMatteo MR, Lepper HS, O'Neil EH Damush TM. The physician's role. Views of the public and the profession on seven aspects of patient care. Arch Fam Med. 1994;3:948-53.

24. Beck RS, Daughtridge R, Sloane PD. Physician-patient communication in the primary care office: a systematic review. J Am Board Fam Pract. 2002; 15:25-38.

25. Piette JD, Schillinger D, Potter MB, Heisler M. Dimensions of patientprovider communication and diabetes self-care in an ethnically diverse population. J Gen Intern Med. 2003; 18:624-33.

26. Flach SD, McCoy KD, Vaughn TE, Ward MM, BootsMiller BJ, Doebbeling BN. Does patient-center care improve provision of preventive services? J Gen Intern Med. 2004;19:1019-26.

27. Greenfield S, Kaplan SH, Ware JE, Yano EM, Frank HJ. Patients'participation in medical care: effects of blood sugar control and quality of life in diabetes. J Gen Intern Med. 1988;5:448-57.

28. Heisler M, Bouknight RR, Hayward RA, Smith DM, Kerr EA. The relative importance of physician communication, participatory decision making, and patient understanding in diabetes self-management. J Gen Intern Med. 2002;17:243-52.

29. Heisler M, Smith DM, Hayward RA, Krein SL, Kerr EA. How well do patients' assessments of their diabetes self-management correlate with actual glycemic control and receipt of recommended diabetes services? Diabetes Care. 2003;26:738-43.

30. Schillinger D, Piette J, Grumbach K, et al. Closing the loop: physician communication with diabetic patients who have low health literacy. Arch Intern Med. 2003;163:83-90.

31. Lewin SA, Skea ZC, Entwistle V, Zwarenstein M, Dick J. Interventions for providers to promote a patient-centred approach in clinical consultations. Cochrane Database Syst Rev. 2005; 1.
32. Reuben DB, Frank JC, Hirsch SH, McGuigan KA, Maly RC. A randomized clinical trial of outpatient comprehensive geriatric assessment coupled with an intervention to increase adherence to recommendations. J Am Geriatr Soc. 1999;47:269-76.

33. Committee on Communication for Behavior Change in the 21st Century. Improving the health of diverse populations, board on neuroscience and behavioral health, institute of medicine of the national academies. Chapter 2: Theory. In: Speaking of Health: Assessing Health Communication Strategies for Diverse Populations. The National Academies Press: Washington, D.C. 2002.

34. Committee on Communication for Behavior Change in the 21st Century. Improving the health of diverse populations, board on neuroscience and behavioral health, institute of medicine of the national academies. Chapter 2: Theory. In: Speaking of Health: Assessing Health Communication Strategies for Diverse Populations. The National Academies Press: Washington, D.C.; 2002:73.

35. Ellis SE, Speroff T, Dittus RS, Brown A, Pichert JW, Elasy TA. Diabetes patient education: a meta-analysis and meta-regression. Patient Educ Couns. 2004;52:97-105.

36. Norris SL, Lau J, Smith SJ, Schmid CH, Engelgau MM. Selfmanagement education for adults with Type 2 Diabetes: a meta-analysis of the effect on glycemic control. Diabetes Care. 2002;27:1159-71.

37. van Dam HA, van der Horst FG, Knoops L, Ryckman RM, Crebolder HF, van den Borne BH. Social support in diabetes: a systematic review of controlled intervention studies. Patient Educ Couns. 2005;59:1-12.

38. Marks R, Allegrante JP, Lorig $\mathbf{K}$. A review and synthesis of research evidence for self-efficacy-enhancing interventions for reducing chronic disability: implications for health education practice (Part II). Health Promot Pract 2005;6:148-56

39. Diabetes Prevention Program (DPP) Research Group. The Diabetes Prevention Program (DPP): description of lifestyle intervention. Diabetes Care. 2002;25:2165-71.

40. Benfari RC. The multiple risk factor intervention trial (MRFIT). III. The model for intervention. Prev Med. 1981;10:426-42.

41. Look AHEAD Research Group. The Look AHEAD study: a description of the lifestyle intervention and the evidence supporting it. Obesity. 2006; 14:737-52.

42. Wing R, Goldstein MG, Acton KJ, et al. Behavioral science research in diabetes: lifestyle changes related to obesitym eating behavior, and physical activity. Diabetes Care. 2001;24:117-23.

43. The Hypertension Prevention Trial Research Group. The hypertension prevention trial (HPT): three-year effects of dietary change on blood pressure. Arch Intern Med. 1990;150:153-62.

44. Prochaska JO, Velicer WF, Rossi JS, et al. Multiple risk expert systems interventions: impact of simultaneous stage-matched expert system interventions for smoking, high-fat diet, and sun exposure in a population of parents. Health Psychol. 2004;23:503-16.

45. Lorig KR, Ritter PL, Laurent DD, Fries JF. Long-term randomized controlled trials of tailored-print and small-group arthritis self-management interventions. Med Care. 2004;42:346-54.

46. Lorig KR, Ritter PL, Laurent DD, Plant K. Internet-based chronic disease self-management. Med Care. 2006;44:964-71.

47. Lorig KR, Sobel DS, Ritter PL, Laurent D, Hobbs M. Effect of a selfmanagement program on patients with chronic disease. Eff Clin Pract. 2001;4:256-62.

48. Newell A, Simon HA. Human Problem Solving. Englewood Cliffs, NJ: Prentice Hall; 1972

49. Newell AS, Shaw C, Simon HA. Elements of a theory of human problem solving. Psychol Rev. 1958;55:151-66.

50. Kahneman D, Slovic P, Tversky A. Judgment under uncertainty: heuristics and biases. New York: Cambridge University Press; 1982.

51. Wing RR, Phelan S. Long-term weight loss maintenance. Am J Clin Nutr. 2005;82:222S-225S.

52. Langer EJ, Imber LG. When practice makes imperfect: debilitating effects of overlearning. J Pers Soc Psychol. 1979;37:2014-24.

53. Sharps MJ, Martin SS. "Mindless" decision making as a failure of contextual reasoning. J Psychol. 2002;136:272-82.

54. Cramer JA. A systematic review of adherence with medications for diabetes. Diabetes Care. 2004;27:1218-24.

55. DiMatteo MR. Variations in patients' adherence to medical recommendation: a quantitative review of 50 years of research. Med Care 2004;42:200-9.

56. Blaum CS, Ofstedal MB, Liang J. Low cognitive performance, comorbid disease, and task-specific disability: findings from a nationally 
representative survey. J Gerontol Ser A Biol Sci Med Sci. 2002;57:M523531.

57. Bruce DG, Casey GP, Grange V, et al. Cognitive impairment, physical disability and depressive symptoms in older diabetic patients: the Fremantle Cognition in Diabetes Study. Diabetes Res Clin Pract. 2003;61:59-67.

58. Elias MF, Elias PK, Sullivan LM, Wolf PA, D'OAgostino RB. Obesity, diabetes and cognitive deficit: the Framingham heart study. Neurobiol Aging. 2005;26(Suppl 1):11-6.

59. Kurella M, Chertow GM, Fried LF, et al. Chronic kidney disease and cognitive impairment in the elderly: the health, aging, and body composition study. J Am Soc Nephrol. 2005;16:2127-33.

60. Manolio TA, Olson J, Longstreth WT. Hypertension and cognitive function: pathophysiologic effects of hypertension on the brain. Curr Hypertens Rep. 2003;5:255-61.

61. Marsh JT, Brown WS, Wolcott D, et al. rHuEPO treatment improves brain and cognitive function of anemic dialysis patients. Kidney Int. 1991;39:155-63.

62. Paul RH, Gunstad J, Poppas A, et al. Neuroimaging and cardiac correlates of cognitive function among patients with cardiac disease. Cerebrovasc Dis. 2005;20:129-33.

63. Trojano L, Antonelli Incalzi R, Acanfora D, Picone C, Mecocci $\mathbf{P}$, Rengo F. Congestive Heart Failure Italian Study Investigators. Cognitive impairment: a key feature of congestive heart failure in the elderly. J Neurol. 2003;250:1456-63.

64. Wu JH, Haan MN, Liang J, Ghosh D, Gonzalez HM, Herman WH. Impact of diabetes on cognitive function among older Latinos: a population-based cohort study. J Clin Epidemiol. 2003;56:686-93.

65. Park DC, Lautenschlager G, Hedden T, Davidson N, Smith AD, Smith P. Models of visuospatial and verbal memory across the adult life span. Psychol Aging. 2002;17:299-320.

66. Brown SC, Park DC. Roles of age and familiarity in learning of health information. Educ Gerontol. 2002;28:695-710.

67. Murray E, Burns J, See Tai S, Lai R, Nazareth I. Interactive Health Communication Applications for people with chronic disease. Cochrane Consumers and Communication Group Cochrane Database Syst Rev. 2007;1 Art. No.: CD004274. DOI 10.1002/14651858.CD004274.pub4.

68. Shumaker SA, Anderson R, Czajkowski SM. Psychological tests and scales. In: Spilker G, ed. Quality of life assessments in clinical trials. New York: Raven Press, Ltd.; 1990:95-113.
69. Ware J, Kosinski M, Keller SD. A 12-item short-form health survey: Construction of scales and preliminary tests of reliability and validity. Med Care. 1996;34:220-33.

70. Hays RD, Kallich JD, Mapes DL, Coons SJ, Carter WB. Development of the kidney disease quality of life $\left(\mathrm{KDQOL}^{\mathrm{TM}}\right)$ instrument. Quality of Life Research. 1994;3:329-38.

71. Buoncristiani U, Cairo G, Giombini L, et al. Dramatic improvement in clinical-metabolic paramenters and quality of life with daily dialysis. Int J Artif Organs. 1989;12(suppl 4):133-6.

72. Hamilton G, Locking-Cusolito $\mathbf{H}$. Original research: the relationship between dialysis adequacy and quality of life: a report of a pilot study. Journal of the Canadian Association of Nephrology Nurses and Technicians. 1998;8:25-9.

73. Chen YC, Hung KY, Kao TW, Tsai TJ, Chen WY. Relationship between dialysis adequacy and quality of life in long-term peritoneal dialysis patients. Perit Dial Int. 2000;20:534-40.

74. Chiou PY, Kuo BI, Lee MB, Chen YM, Chuang P, Lin LC. A programme of symptom management for improving quality of life and drug adherence in AIDS/HIV patients. J Adv Nurs. 2006;55:169-79.

75. Grunfeld EA, Hunter MS, Sikka P, Mittal S. Adherence beliefs among breast cancer patients taking tamoxifen. Patient Educ Couns. 2005;59:97-102.

76. Hughes SL, Weaver FM, Giobbie-Hurder A, et al. Effectiveness of team managed home-based primary care: a randomized multicenter trial JAMA. 2000;284:2877-85.

77. McCorkle R, Benoliel JQ, Donaldson G, Georgiadou F, Moinpour C, Goodell B. A randomized clinical trial of home nursing care for lung cancer patients. Cancer. 1989;64:1375-82.

78. Neff DF, Madigan E, Narsavage G. APN-directed transitional home care model: achieving positive outcomes for patients with COPD. Home Healthc Nurse. 2003;21:543-9.

79. Phillips CO, Wright SM, Kern DE, Singa RM, Shepperd S, Rubin HR. Comprehensive discharge planning with post discharge support for older patients with congestive heart failure: a meta-analysis. JAMA 2004;291:1358-674

80. American Thoracic Society. Statement on home care for patients with respiratory disorders. Am J Respir Crit Care Med. 2005;171:1443-64.

81. Koelling TM, Johnson ML, Cody RJ, Aaronson KD. Discharge education improves clinical outcomes in patients with chronic heart failure. Circulation. 2005;111:179-85. 